\title{
Tourism With the Integration and Development of Vietnam-Southeast Asia
}

\author{
Huynh Quoc Thang \\ Vietnam National University, Ho Chi Minh City, Vietnam
}

\begin{abstract}
Due to its intrinsic and functional characteristics, tourism can be viewed as a special activity that is both an agent and a result, and is itself a concrete manifestation of the process of human the process of developing social life. Especially in the context of industrialization, modernization, and globalization today, along with the "information society and the knowledge economy”, tourism can both be an important cultural interchange channel, and can become a "smoke-free industry" playing a key economic role. Through the development process of the Association of Southeast Asian Nations (ASEAN), especially after the ASEAN Community (AC) was formed (October 2003) with three pillars, especially with the initiative of the Asean Tourism Association (ASEANTA), in fact, it is proving that... By the basis of history-culture and geo-economic conditions have opened up favorable prospects; in coming time through proactive solutions, tourism may become a focal point associated with strategies to accelerate the process of integration of Vietnam and Southeast Asia in order to contribute to the sustainable development of the nation, the region, and the whole world.
\end{abstract}

Keywords: tourism development, integration process, Vietnam and Southeast Asia

\section{Introduction}

As a lecturer in Cultural Tourism in many universities and colleges in Ho Chi Minh City and many other localities nationwide, as well as a member of Executive Committee-Head of Training Board of Tourism Association of Ho Chi Minh City, the author from the perspective of combining culturology with touristology wants to assert that tourism is not only a major economic activity and service in the revolutionary industrial age 4.0 but also one of the ways cultural exchanges, and economic importance in the trend of globalization is expanding as today. For Vietnam and Southeast Asia, a long-standing historical-cultural region has been associated with flesh and blood in many respects; nowadays in the context of the new age, tourism as the dynamic social activity has played a vital role in shaping the integration of the region. The reality has been clearly evident about this and will increasingly require even higher demands on the issue. The content of the article aims to initially contribute to clarifying the situation and proposing solutions related to such problems.

\section{The Integration Process Between Vietnam and Southeast Asia and the Real Status of Tourism Activities}

On July 28, 1995, Vietnam officially became a member of the Association of Southeast Asian Nations

Huynh Quoc Thang, Ph.D., associate professor, Faculty of Cultural Studies, University of Social Sciences and Humanities, Vietnam National University, Ho Chi Minh City, Vietnam. 
(ASEAN). South East Asian countries, which have a special place in Vietnam, have many cultural similarities, have close neighbors, traditions, and are closely associated in terms of security, politics, and economy. ASEAN's accession continues to further strengthen Vietnam's bilateral and multilateral relations with its partners inside and outside the region, contributing to improving and enhancing Vietnam's position in international relations, and facilitate Vietnam's participation in regional and international integration with a deeper and broader scale. In fact, the process of integration does not only promote economic, trade, and investment relations, facilitate the consultation on development, transfer of science and technology, exchange of knowledge and techniques..., it is also possible to directly open opportunities for the Vietnamese economy to develop smoothly and enhance its competitiveness in all cooperation processes between Vietnam and ASEAN in order to contribute significantly to the consolidation of peace, stability, and development of the region and the world.

The ASEAN Charter officially came into effect on December 15, 2008. Vietnam is one of the early countries to ratify and actively participate in joint ASEAN activities to bring this Charter to life. At the same time, Viet Nam also actively contributes to the process of implementing the roadmap for building of ASEAN Community (AC) with three pillars: political-security community, economic community, and socio-cultural community. In line with that process, on the results of the completion of the ASEAN Free Trade Area (AFTA), ASEAN unanimously approved the master plan to step up efforts towards the formation of the ASEAN Economic Community (AEC). Until it was formally established on 31 December 2015, AEC had not only continued to further promote intra-regional trade liberalization and attract foreign investment in ASEAN countries to accelerate the process of regionalization, globalization, but also is accelerated increasingly self-conscious, higher consciousness through cultural communication, political harmony of the communities in the region. A part of the route formed AEC which is adopted at the ASEAN-14 Summit (February 2009), is the development of tourism, one of the 12 priority areas for associating community members. From on the same way, tourism activities can always be considered as one of the direct meaningful contributions to cultural integration in the direction of the items of socio-economic contribution to the realization of ASEAN's common slogan: "One vision, one identity, one community" and even wider, it also is more for the sake of peace, friendship, the environment of life, the human spiritual happiness.

In fact, in the past time, these objectives and contents have been one of the major orientations guiding the entire tourism activities of the ASEAN Member States as well as members of the ASEAN Tourism Association (ASEANTA). At the ASEAN Tourism Forum, held in Manila from January 18 to 22, entitled A Community for Sustainability, Aileen Clemente, Chairman of the ASEANTA prevents conflicts and replaces opposing terms such as "War on Terror" with the slogan "Peace Through Tourism". The call is in the spirit that while terrorism is a global issue, it is important that ASEAN members remain united in building good relations between their neighbors and their relative culture and diversity.... In times of terror and terrorism, tourism plays an integral role in ensuring that a better understanding of the people is needed. It is important that actions work together in a coordinated way towards peace through tourism (Clemente, 2017, November). In that spirit, to celebrate the 50th anniversary of the founding of ASEAN, 10 ASEAN National Tourism Organization (NTOs) have jointly developed a tourism product program called "VISIT ASEAN @ 50: Golden Celebration”. The program was officially launched at the ASEAN Tourism Forum in Singapore on 18 January and lasts until 31 December, 2017. This is a "golden anniversary" program with 50 cross-border travel experiences to help travelers to visit Southeast Asia including all 10 ASEAN member countries as a "channel” for exchanges and connections of the 
culture, economy, and society between the people in the region and the world (VISIT ASEAN @ 50: Golden Celebration, 2017, December).

In the whole process of regional integration on socio-economic, with internal forces and cultural achievements, after a long period in the war, Vietnam tourism has been overcome with many difficulties and challenges to formally join the process of development with a new posture. The tourism industry of Vietnam was formed very early, from the year 1960 in the North of socialism, even while the country is still divided war so that tourism activities in this stage have no conditions for real development. After 1975, although basically there was peace and unity, in the bureaucratic subsidy mechanism, the development of Vietnam tourism in general was also limited. Only after 1986, with the way of "Doi moi", in essence, the abolition of the subsidy mechanism to move to market mechanism simultaneously with the policy of "Open door", the process of integration with the region and the world has the important conditions for Vietnam's tourism to really take off in the new stage. A landmark marking the official development of Vietnam's tourism in the process of integration with the region and the world is the Vietnamese Cultural and Sports Festival on the occasion of the 15th anniversary of the victory April 30 (1975-1990) and the 100th anniversary of the birth of President Ho Chi Minh (1890-1990) as the National Liberation Hero-The World Cultural Celebrity - The United Nations Educational, Scientific, and Cultural Organisation (UNESCO) has just recognized. This is the first national tourism festival of Vietnam by the Ministry of Culture, Information, Sports and Tourism at that time in collaboration with the People's Committee of Ho Chi Minh City held in Ho Chi Minh City ${ }^{1}$. With a short time before April 30, 1975, and after May 19, 1975, a few days, the festival has attracted nearly 300,000 international visitors (including visitors of some Southeast Asia), which is unprecedented ${ }^{2}$. Since then, through many stages of development, along with the deepening integration of Vietnam with other Southeast Asian countries, regional tourism has always been considered as a big and potential market. According to the latest statistics, visitors from Southeast Asian countries, such as Thailand, Laos, Cambodia, Malaysia, the Philippines, and Singapore reached 1,461,172 arrivals, accounting for $14.59 \%$ of total international arrivals in $2016^{3}$. It is noteworthy that with the strength of a coastal nation running from north to south along with thousands of large and small islands, stretched beaches, diverse ecosystems, and beautiful bays are famous on the tourism map in the world, such as Ha Long Bay, Nha Trang Bay, Vinh Hy Bay, Lang Co Bay..., Vietnam has many favorable conditions for the development of marine tourism; not to mention, Vietnam has a convenient location between the two largest cruise tourism centers in Hong Kong and Singapore. Therefore, the 3,200 km long coastal zone can be considered as a "big door" for Vietnam to have more potential and access to regional and international tourism through the East Sea (Khánh, 2017, December). Looking at the overall relationship, Vietnam's tourism growth rate is the second highest in comparison with other countries in Southeast Asia. In the period 2011-2016, Vietnam's tourism grew by 11\%, only lower than Myanmar (37\%) and Cambodia (12\%). In 2016, Vietnam had the highest growth rate in the region (26\%), while Indonesia was 16\% (second highest), Philippines (11\%), Thailand (9\%), Singapore (8\%), Cambodia, and Malaysia (4\%). However, besides the strength of cultural resources and official tourism (grade 30), natural resources (34th), price competitiveness (35th), human and

\footnotetext{
1 This festival was held at Tao Dan Cultural Park (now Ho Chi Minh City Cultural Park). At that time, the author of this article was a participant in the Festival Organizing Committee as deputy head of content.

2 Specific number of international visitors to Vietnam before (rounded): 1975: 36,000 visitors; 1980: 41,000 visitors; 1985:

51,000 visitors; 1989: 88,000 visitors (Source: Ministry of Culture, Information, Sports and Tourism, 1990).

${ }^{3}$ Vietnam National Administration of Tourism-Ministry of Culture, Sports and Tourism, 2017.
} 
labor market (grade 37), Vietnam's tourism still has many low ranked indicators: environmental sustainability (class 129), quality of tourism infrastructure (class 113), priority for the tourism sector (ranked 101), and the level of international openness (rank 76). In particular, the biggest constraints for Vietnam's tourism sector are: the quality of tourism infrastructure (113th); index of entry visa (rank 116th, lowest among ASEAN countries); and government spending on tourism (114th) ${ }^{4}$. Currently, Vietnam exempts entry visas for citizens of 22 countries, but Indonesia exempts 169 countries and territories, Singapore 158, Philippines 157, Malaysia 155, and Thailand exempts citizens of 61 countries and territories. In addition, Malaysia has 35 representative offices abroad; Thailand has 28 offices, Singapore 23 offices, while Vietnam has no representative office abroad. Overall, the number of international visitors to Vietnam in 10 ASEAN countries is still low: In 2016, Vietnam ranked fifth in terms of number of international visitors with over 10 million arrivals, equaling 31\% compared with Thailand (32.6 million), equal to 37\% of Malaysia (26.8 million), 61\% of Singapore (16.4 million), 83\% of Indonesia (12 million) (Phuong, 2017, November). In such a general context, it is clear that tourism in Vietnam is and will continue to struggle to make greater efforts to promote the integration process. As a result, many tourism conferences of the government, localities throughout the country, and many documents on tourism are issued.... Most recently, the Politburo-Central Committee of the Communist Party of Vietnam issued Resolution No. 08-NQ/TW dated January 16, 2017 on tourism development to become a spearhead economic sector with many concerns and major orientation is one of the important foundations to further promote the integration and development process of Vietnam in the region and the world.

\section{Basic and Orientation of Tourism Development in the Process of Vietnam—Southeast Asia Integration}

First, as we all know, Southeast Asian nations have a special relationship with many social and cultural traits with South Asian countries (central is India) and Northeast Asian countries (central is China), but at the same time it is a historical-cultural area with specific characteristics. In particular, through long-standing research on geographic and historical relationships, many scientists often talk about "Southeast Asian cultural and historical structure" of Vietnam and affirm "Vietnam is a miniature Southeast Asia". Vietnamese-Southeast Asian integration and development in all fields is therefore very meaningful and strategic. Experiencing historical challenges, from war to natural calamities, economic and financial turmoil, etc.... all show that "Southeast Asia exists as a 'living body' that each of the countries in the region is a part organism that has an organic relationship to the body itself" (Huynh, 2006, p. 115). That is, when entering the new century, new opportunities and challenges are opening up, tightening the cooperation for the comprehensive and sustainable development of the countries in the region as well as for the entire region is increasingly becoming one of the most meaningful, objective, and urgent social processes. Addressing the development of tourism in the integration process of Vietnam and Southeast Asia is an important element contributing to the implementation of this strategy and it has very clear historical, scientific, and practical bases.

In order to implement the above strategy, a leading strength of Vietnam and Southeast Asian countries should be thoroughly promoted as the potential capital of cultural heritage, both tangible and intangible with

\footnotetext{
${ }^{4}$ In 2016, Vietnam spent only \$2.5 million to promote national tourism destinations while Thailand, Singapore, and Malaysia spent about \$100 million for this activity (Source: Vietnam National Administration of Tourism—Ministry of Culture, Sports and Tourism, 2017).
} 
many identities, unique, attractive no less than anywhere else in the world. In addition, the natural resources and the human resources of Vietnam as well as the whole region in general are really an invaluable treasure of pristine, primitive, high biodiversity (both vegetation, as well as human beings...), the richness of terrain, geomorphology. In particular, the country in addition to the general features as mentioned above, there are other ones about nature, people, history, culture. It has many unique features, especially a culture of culinary special..., moreover, this country is considered as a place where the social environment is friendly and safe, etc... These are the most important resources to develop tourism and in fact, tourism in Vietnam and Southeast Asia is generally regarded as having great potential, high attractiveness, and dynamic development, which is a very meaningful content for cooperative strategy and sustainable development of the whole region. Developing tourism among Southeast Asian nations is one of the best ways to be able to create more and more understanding and closer ties between peoples and countries in the region with the orientation of

through cultural tourism, aware of the inherent cultural values, it has become a major factor in the quality of tourism products, as well as the most sacred "the cord bearing Human beings" that contributes to the tightening process of collaboration and solidarity which are mutually beneficial, which is one of the most positive and immediate directions for the communities in the region. (Huynh, 2006, p. 116)

That makes more sense in the context of countries in the region and the world which are and will be facing the process of "Globalization" simultaneously with the "Global issues" increasingly fierce as the variable climate change, war (terrorism, nuclear risk, etc.), poverty, and social disparity, etc. Tourism development (cultural orientation) to create "doors" for peace and prosperity that having been expanded to contribute to socio-economic development, protection of the natural and human ecological environment, preservation and promotion of all biological and cultural diversity, contributing to the improvement of happiness and social benefits and development of community life for each country as well as throughout the region ... all the work is both practical and thoughtful a long time.

Secondly, the major objectives and orientations as mentioned undoubtedly pose the issue of bilateral and multilateral cooperation among ASEAN countries in addition to the general socio-economic action plans based on the "three pillars" as determined; it can also be associated with the strategy of exploiting and promoting tourism as one of the effective solutions to accelerate and deepen the integration process in the region. Accordingly, the development of tourism in each country contributes to the development of tourism in the region and vice versa is important. At the same time, "assignment and decentralization of regional, national, local (province, city) to both develop tourism on the spot and contribute to the development of tourism throughout the region is doing the necessary" (Huynh, 2006, p. 117). Of course, other specific things from an outsourcing perspective are that tourism development must begin with a concrete plan to implement "Diversification and quality improvement for tourism product" meet the needs of the tourism market combined with promoting the propaganda and regularly updating information on this market. In addition, building relationships with partners (Outbound Travel Agents, Tour Operator...) in countries around the region based on the sense of responsibility, reputation, handle all work quickly, accurately...all are very necessary. From an insight perspective, the construction of the tourism industry with tour operators and travel agencies includes all types of accommodation, restaurants, transportation companies, entertainment services, shopping...need to invest more strongly in both quantity and

\footnotetext{
${ }^{5}$ One of Vietnam’s National Tourism Action Plans since 2000.
} 
quality; in it, the food service is both a strength and a problem that still needs to be more deeply concerned not only with food security or organization...but also meet the needs of different types of food. For example, in 2016, the number of 1,461,172 visitors from Southeast Asian countries came to Vietnam; the most is Malaysia (reaching 407,574, accounting for nearly 30\%) of which a large number of people in the community of Islamic but Islamic Halal restaurant system are only available in big cities (10 places in Ho Chi Minh City, 3 places in Hanoi), other localities almost none ${ }^{6}$. Therefore, it is necessary to invest in developing more Halal restaurants in the key tourist areas.... In addition to the development of infrastructure, material and technical standards for tourism, the construction of management staff, tourism operations, especially Tourguide professional suitable for each customer of each market is very decisive.... Moreover, the promotion of investment promotion, tourism promotion, building a national tourism brand on the basis of the tourism brand in the region in the process of deepening integration with the region and the world is extremely necessary. One of the most important experiences is the branding of tourism products; the image of local tourism must be based on the characteristics of prominence and high characteristics while exploiting the specific characteristics of culture to invest in hi-tech application for promotion activities, to exploit optimum information technology, modern media and coordinate well with international partners in promoting tourism... For example, the film Kong-Skull Island was filmed in Ninh Binh, Quang Ninh, and Quang Binh, and is being screened in many parts of the world, making it an important contribution to the local tourism brand as well as to Vietnam tourism. Similar but more profound meaning, the image of nature, the landscapes, and the traditional beauty of the local people Phu Yen based on the basis of the "soul", shines from the values of folk culture inherent in the movie Yellow Flowers on Green Grass which has become a valuable brand of local tourism and tourism in Vietnam.

Thirdly, in the coming period, the coordination among countries in the region in order to enhance the efficiency of the state management of tourism, the tourism marketing and promotion in a common market in order to ensure a healthy and sustainable tourism business environment in the whole area can still be considered as a "solid support" needed for the whole issue. According to such requirements, the inspection, survey, and evaluation activities are conducted regularly to ensure that the quality of tourism services in each country will need step by step towards the goal more and more consistent with the standards of the general price in a unified tourism market of the region in the near future, proceeding to price stability in order to bring about the increasing competitiveness of regional tourism compared to the regions other parts of the world. In addition, other specific issues, such as extending visa procedures for travelers across the region, building a common market for training and the use of tourism human resources... all need to be calculations coming as a part that cannot be ignored in the overall strategy. At the same time, the development of community-based tourism in order to facilitate the participation of local residents not only is preserving and promoting the value of natural resources and human resources for tourism development, but also raising awareness and capacity to behave in tourist communication for international tourists from countries in the region and around the world, creating and protecting the best image of the country and its people of Southeast Asia in general and cultural beauty of each locality in particular....

\section{Conclusions}

In general, during the integration process in the formation and development of ASEAN, Vietnam, in

\footnotetext{
${ }^{6}$ Data are based on Vietnam National Administration of Tourism—Ministry of Culture, Sports and Tourism \& Tourism Department of Ho Chi Minh City, 2017.
} 
comparison with some Southeast Asian countries, was one of the youngest members but also made a strong mark for contributing to the Association's continuous growth in both quantity and quality, in which tourism activities of Vietnam is one of the factors that have increasingly active role. Due to its nature, tourism has been affirmed as part of a strategy to accelerate the integration of Vietnam and Southeast Asia in order to contribute to the development of the country in relation to the common development of the region and the whole world. With the view of "Sustainable tourism development; preserve and promote the cultural heritage and traditional values of the nation; environmental protection and nature...”, Resolution of the Politburo-Central Committee of the Communist Party of Vietnam No. 08-NQ/TW, January 16, 2017 clearly defined goals:

By 2020, tourism has become a key economic sector, creating a driving force for socio-economic development; having professionalism and having a system of material and technical bases which are relatively synchronous and modern; high quality, diversified and branded tourism products bearing the national cultural identity, competing with other countries in the region. Strive to 2030 ... Vietnam is a group of countries with leading tourism development in Southeast Asia.

It is clear that such great orientations have placed Vietnam's tourism at an important position in the sphere of one of the "spearheads" not only creating economic breakthroughs but also a positive motive force of the association process of Vietnam's cultural and social integration with other countries in the region in a way both competition and cooperation for development. It will also be very meaningful in line with the trend Vietnam and ASEAN countries increasingly asserting their position in the economic, political, and social life of the region as well as throughout the world through the process integrating and developing more and more deeply, with higher quality and efficiency, in which tourism is a social activity with important role and position.

\section{References}

Binh, N. P. (2017, November 14). The relationship between Vietnam and ASEAN future. Retrieved from http://www.dav.edu.vn/en/introduction/missions.html?id=316:so-19-he-viet-nam-asean-va-velvet-van-de-dat-in-a-lai

Clemente, A. (2017, November 25). Replacing the "war on terror" with "peace through tourism". Retrieved from http://www.aseanta.org/index.php/component/content/article/8-news-and-updates/28-aseanta-s-female-president-tells-touris m-ministers-replace-terrorism-with-peace-through-tourism

Phuong, L. (2017, November 14). Where is Vietnam's tourism in ASEAN? Retrieved from http://vietnamtourism.gov.vn/ index.php/items/24110

Thang, H. Q. (2006). Cultural tourism of Vietnam-Southeast Asia with strategic cooperation and sustainable development of the region. In Proceedings of the Scientific Seminar ASEAN Community: From Idea to Reality (pp. 115-117). Open University of HCMC-Statistics Publishing House.

Trang, K. (2017, December 25). Positive signals for the market of cruise ship Vietnam. Retrieved from http://vietnamtourism.gov.vn/index.php/items/24187

Visit the ASEAN 50 Campaign @ to announce 50 tourism experiences for 2017. (2017, December 20). Retrieved from http://www.esanta.org/index.php/component/content/article/8-news-and-updates/38-new-condolence-message-2 